\title{
O impacto da crise econômica nas finanças públicas estaduais: o caso de Minas Gerais
}

The economic crisis impact on states' public finance: the case of Minas Gerais

Raimundo Leal Filho*

Lúcio Barbosa ${ }^{\dagger}$

\begin{abstract}
Resumo
O presente estudo visa a avaliar os impactos da recessão econômica de 2015-2017 sobre as finanças públicas estaduais de Minas Gerais. A análise se concentra, em particular, na discussão dos impactos da severa contração do nível de atividade econômica sobre a arrecadação tributária. A metodologia utilizada consiste em (i) mensurar a magnitude da perda de PIB associada à crise econômica, identificando a correspondente frustação na arrecadação dos principais tributos relacionados à atividade econômica e (ii) examinar a evolução das receitas e despesas orçamentárias no mesmo período. 0 estudo sugere que, assim como em outros entes federados (em particular, o Rio de Janeiro), inevitavelmente, a solução da crise fiscal requer a mediação da União, onde se concentra a maior parcela da arrecadação tributária.
\end{abstract}

Palavras-chave: Crise econômica; Crise fiscal; Minas Gerais.

\begin{abstract}
This paper quantifies the fiscal implication of the economic crisis on fiscal imbalances of Minas Gerais from 2015 to 2017. Particularly, it focus on measuring the impact of the recent economic downturn on tax revenues. The methodology consist on (i) quantifying the GDP fall due to economic crisis and the corresponding contraction of tax revenues and (ii) assess the evolution of budget expenditures and revenues. The results suggest that the solution for Minas Gerais fiscal crisis, as well as other subnational entities (specially, Rio de Janeiro), depends upon central government rescue, since the Brazilian taxes system is not enough decentralized.
\end{abstract}

Keywords: Economic crisis; Fiscal crisis; Minas Gerais.

JEL Classification: E62; H72.

\footnotetext{
* Pesquisador da Fundação João Pinheiro (FJP), e-mail: raimundo.sousa@fjp.mg.gov.br.

+ Pesquisador da Fundação João Pinheiro (FJP), e-mail: lucio.barbosa@fjp.mg.gov.br.
} 


\section{Introdução}

A recessão econômica brasileira, entre o segundo trimestre de 2014 e o quarto trimestre de 2016 (CODACE), aliada à lenta recuperação em 2017, reflete o fraco desempenho econômico de todas as unidades da federação. Em maior ou menor grau, as 27 unidades da federação apresentaram queda real na produção.

Em Minas Gerais, no ano de 2015 a queda do PIB foi de 4,3\%. Todos os setores registraram crescimento negativo, sendo que a indústria foi o setor mais afetado, retraindo 6,2\%. Em 2016, as condições econômicas continuaram se deteriorando, ainda que em ritmo mais lento. A queda foi de $1,8 \%$ e novamente o comportamento da indústria se destacou negativamente, decrescendo $4,4 \%$. O resultado só não foi pior porque o desempenho da agropecuária foi bastante positivo, alcançando o crescimento real de 8,9\% (FJP, 2018).

Depois de dois anos de quedas consecutivas, em 2017 a economia mineira cresceu $0,6 \%$. Dessa vez foi o setor de serviços que impediu que o resultado fosse mais uma vez negativo. Portanto, depois de uma variação negativa de 6,1\% no biênio 2015-2016, a economia de Minas Gerais conseguiu devolver menos de $10 \%$ da retração registrada.

Nesse cenário, a situação fiscal dos estados, que é historicamente frágil (LOPREATO, 2008), foi à bancarrota. Atrasos de pagamento aos servidores, dificuldade de honrar compromissos, déficits crescentes têm sido a tônica dos últimos anos em Minas Gerais (Rio de Janeiro e Rio Grande do Sul também). No âmbito nacional, a questão fiscal tem pautado o debate econômico. Inclusive, existe um certo consenso que o encaminhamento de uma solução para o problema fiscal seria pré-condição para a retomada do crescimento econômico tanto no caso da União quanto dos estados. No entanto, os resultados recentes do PIB abaixo do esperado ${ }^{1}$, mesmo com a recente queda da taxa de juros real e do risco-país, enfraqueceram, em parte, o viés fiscalista. De qualquer forma, a situação fiscal da União e dos estados continua grave.

No primeiro caso, os resultados primários negativos (que desconsideram o pagamento dos juros da dívida pública) têm se avolumado desde 2014, sendo que tanto em 2016 quanto em 2017 o déficit primário foi superior a 100 bilhões, equivalente à aproximadamente $2 \%$ do PIB. O resultado primário estrutural, que ajusta para os efeitos de eventos não recorrentes sobre receitas (por exemplo, programas de regularização tributária ou de venda de ativos) e despesas e considera o PIB tendencial, também está negativo em cerca de $2 \%$.

Adicionalmente, para a estabilização da razão dívida/PIB, calcula-se que seria necessário um superávit primário entre $2 \%$ e $3 \%$ do PIB. Essa conta leva em consideração a diferença entre a taxa real de juros paga pelos títulos do Tesouro e a taxa recebida pelos seus créditos e pelas reservas internacionais. Ou seja, seria necessário, além de reverter a trajetória ascendente dos gastos públicos, reduzi-los em pelo menos $4 \%$ do PIB, isto é, em mais de 400 bilhões.

A emenda constitucional 95, promulgada em 2016, foi a resposta que a equipe econômica do governo atual implementou. Grosso modo, ela congela, a partir de 2018, os

\footnotetext{
${ }^{1}$ Ao longo deste ano a estimativa de crescimento do PIB já se reduziu em cerca de $1 \%$ (ao invés de próximo de $3 \%$, o consenso atual é que a economia cresça menos do que $2 \%$ ).
} 
gastos reais por 20 anos. Dessa forma, no longo prazo, desde que o PIB cresça em termos reais, a razão dívida/PIB se estabilizará e, eventualmente, reduzirá ${ }^{2}$. Observa-se que nos últimos anos, quando se considera a dívida bruta do governo geral, essa relação tem se deteriorado rapidamente, superando os $75 \%$.

No caso dos estados, a questão é ainda mais delicada. A despesa líquida com pessoal (ativos e inativos) consome boa parte do orçamento, superando os $50 \%$ da receita corrente líquida ( $\mathrm{RCL}$ ), que desconta as transferências constitucionais dos estados para municípios. No caso de Minas Gerais, do Rio Grande do Sul e do Rio de Janeiro, esses gastos superam 70\%. Além disso, o sistema previdenciário dos estados é, via de regra, deficitário, sendo que os estados, em 2016, tiveram que aportar cerca de $11 \%$ da $\mathrm{RCL}^{3}$.

Pelo lado da receita, a capacidade de endividamento dos estados é limitada. A LRF estabelece um teto de $200 \%$ da RCL. Aqui, novamente, Minas Gerais, Rio de Janeiro e Rio Grande do Sul estão perto ou acima do teto. A crise econômica, por sua vez, derrubou a arrecadação dos estados.

O resultado da queda de arrecadação combinada com a rigidez orçamentária são os crescentes déficits fiscais. A solução, no caso dos estados, tem sido protelar medidas estruturantes e recorrer a venda de ativos, aumento dos restos a pagar (despesas reconhecidas, mas não pagas), atrasos no pagamento do servidor, utilização de depósitos judiciais, renegociação de dívidas etc.

É nesse contexto que se insere o presente estudo. Seu objetivo é avaliar os impactos da recessão econômica de 2015-2017 sobre as finanças públicas estaduais de Minas Gerais. A análise se concentra, em particular, na discussão dos impactos da severa contração do nível de atividade econômica durante o triênio 2015-2017 sobre os resultados agregados das finanças públicas estaduais. A metodologia proposta para viabilizar essa avaliação foi composta de duas estratégias principais: (i) mensuração da magnitude da perda de PIB associada à crise econômica no triênio 2015-2017, identificando a correspondente frustação na arrecadação dos principais tributos relacionados à atividade econômica (ICMS, PIS e COFINS) e (ii) análise da evolução dos principais agregados de receitas e despesas orçamentárias no mesmo período.

Na seção seguinte, primeiro, descreve-se a estratégia metodológica para estimar o PIB tendencial, e, segundo, discutem-se os resultados. A seção 3 apresenta as estimativas de perda de arrecadação associada à crise econômica. Na sequência, evidencia-se a crise fiscal atual do estado, examinando, mais detalhadamente, a dinâmica das despesas orçamentárias. Ao final, são apresentadas as conclusões desse estudo.

\section{Crise econômica de Minas Gerais}

Nesta seção, mensura-se o impacto da recessão econômica de 2015-2017 sobre a economia mineira. Além dos resultados para a economia do estado, são apresentados, para fins de comparação, os resultados para a economia nacional. Apresentam-se, primeiro, os

\footnotetext{
${ }^{2}$ Não se discute aqui o mérito dessa emenda, a qual repercutiu amplamente no meio acadêmico. Para uma discussão detalhada, ver Pereira et al. (2017).

${ }^{3}$ Ver boletim econômico da FIRJAM (2017).
} 
aspectos metodológicos envolvidos na mensuração do PIB potencial. Em seguida, os resultados.

\subsection{Estimativa da perda de PIB em Minas Gerais: aspectos metodológicos}

Para a estimativa da perda do PIB resultante da contração do nível de atividade econômica, a metodologia adotada em Gordon ${ }^{4}$ (2017) foi adaptada para o estudo do caso da economia de Minas Gerais. A análise se concentra no período de 2015 a 2017, quando se observou uma das mais severas contrações do nível de atividade da economia brasileira para todo o período em que se dispõem de estatísticas confiáveis sobre a taxa de variação do PIB a preços constantes. ${ }^{5}$

Essencialmente, essa metodologia propôs o confronto entre o nível do PIB, em termos reais, extrapolado para um determinado período a partir da sua tendência de longo prazo, com o nível do PIB mensurado nas estatísticas oficiais. Em relação a outras metodologias disponíveis, ${ }^{6}$ a principal justificativa para essa escolha foi a sua simplicidade, que viabilizou sua operacionalização num prazo muito curto de tempo, e à facilidade de compreensão do seu significado por parte de um público mais amplo, para além dos limites estreitos de uma linguagem técnica associada aos saberes acadêmicos especializados.

Dada a sensibilidade da tendência de longo prazo em relação ao período base escolhido, decidiu-se retroagir os dados o máximo possível, respeitados os seguintes critérios: primeiro, de coerência quanto às possibilidades de harmonização de diferentes metodologias utilizadas no cálculo do PIB das UFs; segundo, de identificação da presença de denominadores mínimos comuns na caracterização do regime de política macroeconômica ao longo de todo o período escolhido.

Quanto ao primeiro critério, optou-se por produzir numa primeira aproximação ${ }^{7}$ uma série histórica longa para todo o período 1995-2014. Com relação ao segundo critério $^{8}$,

\footnotetext{
${ }^{4}$ Essa metodologia foi utilizada para mensurar a magnitude do "grande salto de produtividade" da economia dos Estados Unidos no período 1928-72.

${ }^{5}$ Qual seja, o período iniciado em 1901 (Reis et al., 2006, pp. 509-538). Considerando os dados anuais, nos episódios mais graves de recessão da história econômica brasileira recente, o PIB a preços constantes retraiu 5,3\% entre 1929 e 1931, 6,3\% entre 1980 e 1983, e 3,8\% entre 1989 e 1992 (IBGE, 2006); no último episódio, entre 2014 e 2016, retraiu 6,9\%.

${ }^{6}$ Silva-Filho (2001); Souza Jr. (2005); Souza Jr. e Caetano (2013);

${ }^{7}$ Nesse caso, seriam mantidos os últimos dados disponíveis, referentes ao índice de volume encadeado do PIB das UFs divulgados em 2012 para o período 1995-2002, embora este índice já tenha sido revisado para o Brasil. Desta forma, os critérios mínimos de harmonização das metodologias seriam atendidos, sem, no entanto, pretender que a atualização da primeira retropolação (1995-2002) à metodologia do Sistema de Contas Regionais do IBGE na Referência 2010 esteja completa. Vários passos adicionais seriam necessários para completar esse procedimento, o que iria muito além do escopo desse trabalho: primeiro, seria preciso ajustar os índices de volume do PIB das UFs (divulgados em 2012) à revisão, que já foi consolidada no Sistema de Contas Nacionais do IBGE, do índice de volume do PIB do país no período 1995-2002; segundo, seria necessário ajustar os valores a preços correntes e constantes dos Impostos Indiretos sobre Produtos líquidos de Subsídios, do Valor Bruto de Produção Setorial, do Consumo Intermediário Setorial e do Valor Adicionado Bruto Setorial para todas as UFs aos novos dados consolidados para o país no período 1995-2002.

${ }^{8}$ Destaca-se o papel das particularidades do período 2002-2014 que resultaram na aceleração do ritmo de crescimento econômico com melhoria da distribuição de renda na economia brasileira
} 
considerou-se que o conjunto do período 1995-2014 também atende ao critério de identificação da presença de denominadores mínimos comuns derivados da consolidação do processo de estabilização macroeconômica. ${ }^{9} \mathrm{O}$ gráfico 1 , abaixo, apresenta os dados relativos às taxas de crescimento real do PIB do Brasil e de Minas Gerais, para todo o período 19962017, que serão utilizados ao longo desse trabalho.

Gráfico 1. Taxas de variação (\%) anual do índice de volume do PIB, Minas Gerais e Brasil (19962017)

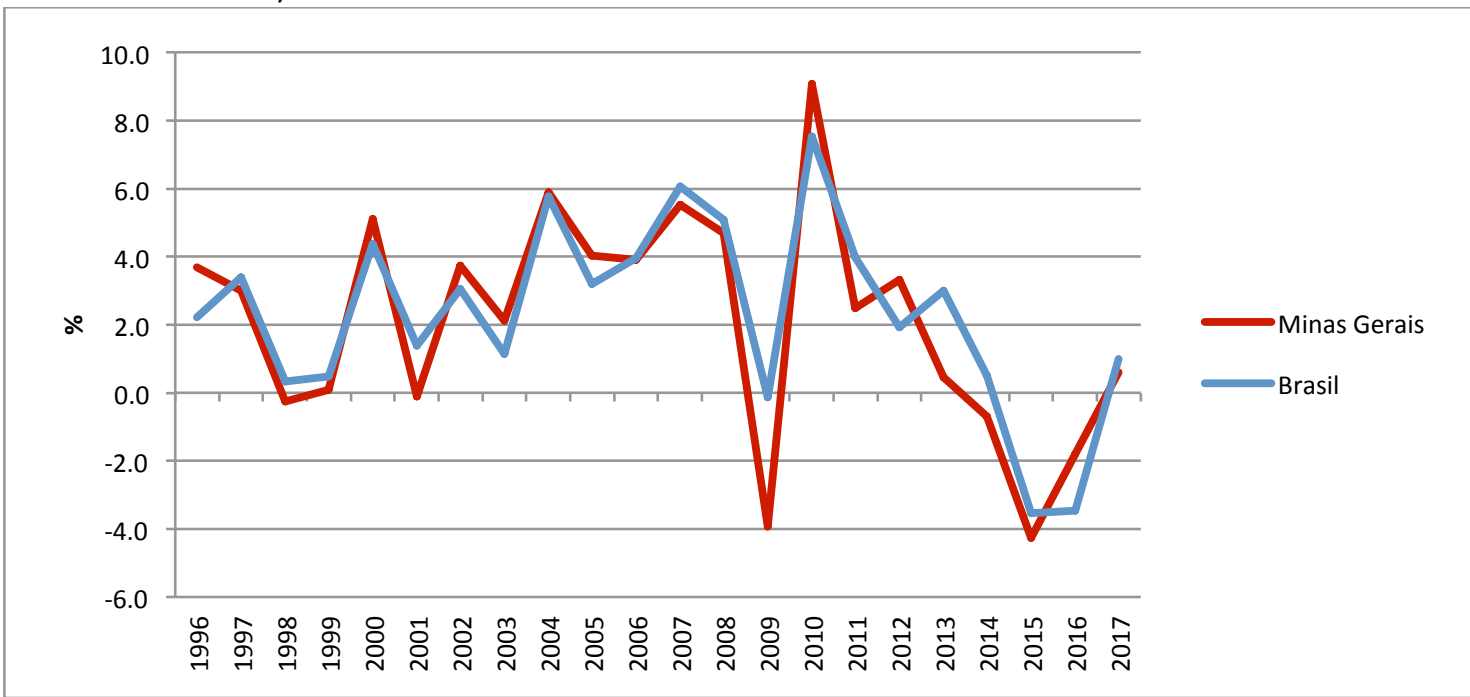

Fonte: Elaboração própria a partir de dados da FJP-MG e IBGE.

O próximo passo, necessário para melhor apropriação da metodologia de Gordon (2017), exige a correção do efeito da desaceleração do ritmo de crescimento populacional ocorrido no período. A sociedade brasileira experimentou, ao longo do período considerado, a assim chamada segunda fase da transição demográfica. O resultado foi a rápida diminuição da taxa de crescimento da população (Barbosa Filho et al., 2016).

Durante essa transição, a proporção de crianças e adolescentes na população total reduziu-se muito rapidamente, ao mesmo tempo em que a proporção de idosos aumentou lentamente. Daí que, enquanto a produtividade do trabalho apresentava um progresso bastante limitado durante a maior parte do período 1995-2014, o número de trabalhadores (extraídos da população em idade ativa) aumentava mais depressa do que a população total.

A contribuição da transição demográfica para o crescimento do PIB per capita, no Brasil e em Minas Gerais, foi significativa, mas é cada vez menor. Eventualmente (por volta de 2030, quando se esgotará o chamado bônus demográfico ${ }^{10}$ no Brasil), ela irá mudar de sinal, passando a implicar uma taxa de variação para o PIB per capita menor do que a da produtividade do trabalho.

\footnotetext{
9 Destaca-se que, excepcionalmente, o período 2002-2014 foi marcado pela aceleração do ritmo de crescimento econômico com melhoria da distribuição de renda na economia brasileira. Para uma definição conceitual dos regimes de política macroeconômica ver Oreiro e D’agostini, 2017.

${ }^{10}$ Sobre esse ponto, vale consultar a análise pioneira de Rios-Neto (2005).
} 
A partir das projeções da população das UF's por sexo e idade ${ }^{11}$ disponibilizadas pelo o IBGE, referentes ao período 2000-2030, construiu-se uma série atualizada para os valores do PIB per capita das UF's inteiramente compatível com a série correspondente para o Brasil. Os dados revelam que o crescimento do PIB per capita em Minas Gerais foi de $1.6 \%$ a.a. e no Brasil de $1.76 \%$ a.a.

Em síntese, a metodologia aqui utilizada consiste da utilização das taxas de crescimento do PIB per capita como base para a identificação da tendência de longo prazo no triênio 2015-2017. Sobre essa base, foram adicionadas as taxas de crescimento populacional projetadas pelo IBGE para o mesmo período (2015-2017). Então, construíram-se as projeções para a tendência de longo prazo das taxas de crescimento real do PIB, tanto para a economia brasileira quanto a de Minas Gerais.

\subsection{Estimativa da perda de PIB em Minas Gerais: resultados}

Para estimar a perda de PIB em Minas Gerais e no Brasil, foram comparados os dados observados e a extrapolação da tendência de longo prazo durante o período 1995-2017. Os gráficos 2 e 3 ilustram os resultados.

Nesse confronto, verificou-se que o nível de atividade econômica em Minas Gerais esteve acima da sua tendência histórica nos anos 1995-1997, 2005-2008 e 2010-2014. Já os anos 1998-2004, 2009 e 2015-2017 registraram uma conjuntura de fraco desempenho da geração de produto agregado local. É possível observar, inclusive, que a magnitude da crise recente supera em larga medida os episódios anteriores de recessão no período 1995-2017 (Gráfico 2).

Gráfico 2. Índice de volume do PIB (observado e tendência de longo prazo) - Minas Gerais 1995-2017 - (base: 1995=100)

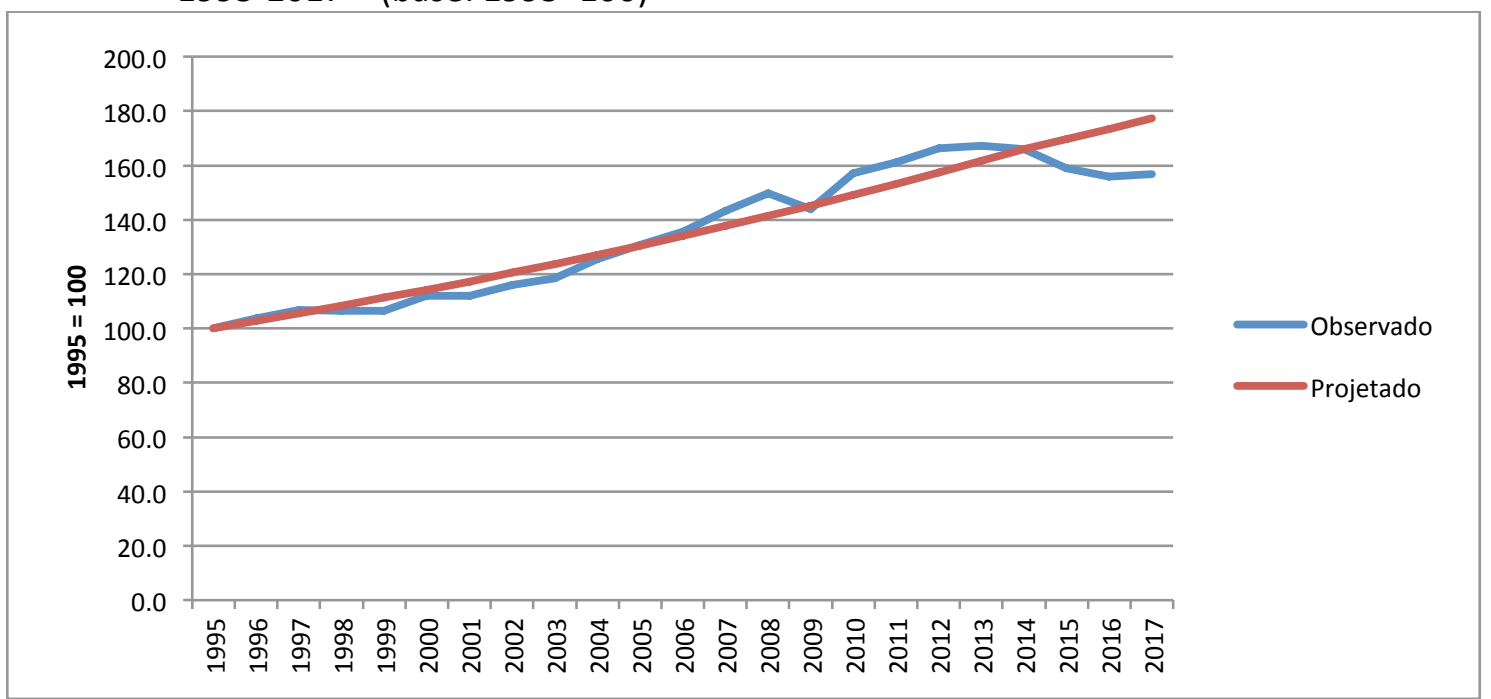

Fonte: Elaboração própria a partir de dados da FJP-MG.

${ }^{11} \mathrm{O}$ detalhamento dos procedimentos metodológicos consta da publicação do IBGE (2013); para o download das bases de dados, confira: <https://www.ibge.gov.br/estatisticasnovoportal/sociais/populacao/9109-projecao-da-populacao.html?=\&t=resultados $>$ (acesso em 22/03/2018). No caso das UFs, para o período anterior a 2000 é preciso recorrer aos dados de IBGE (2008). 
Gráfico 3. Índice de volume do PIB (observado e tendência de longo prazo) - Brasil - 19952017 - (base: $1995=100$ )

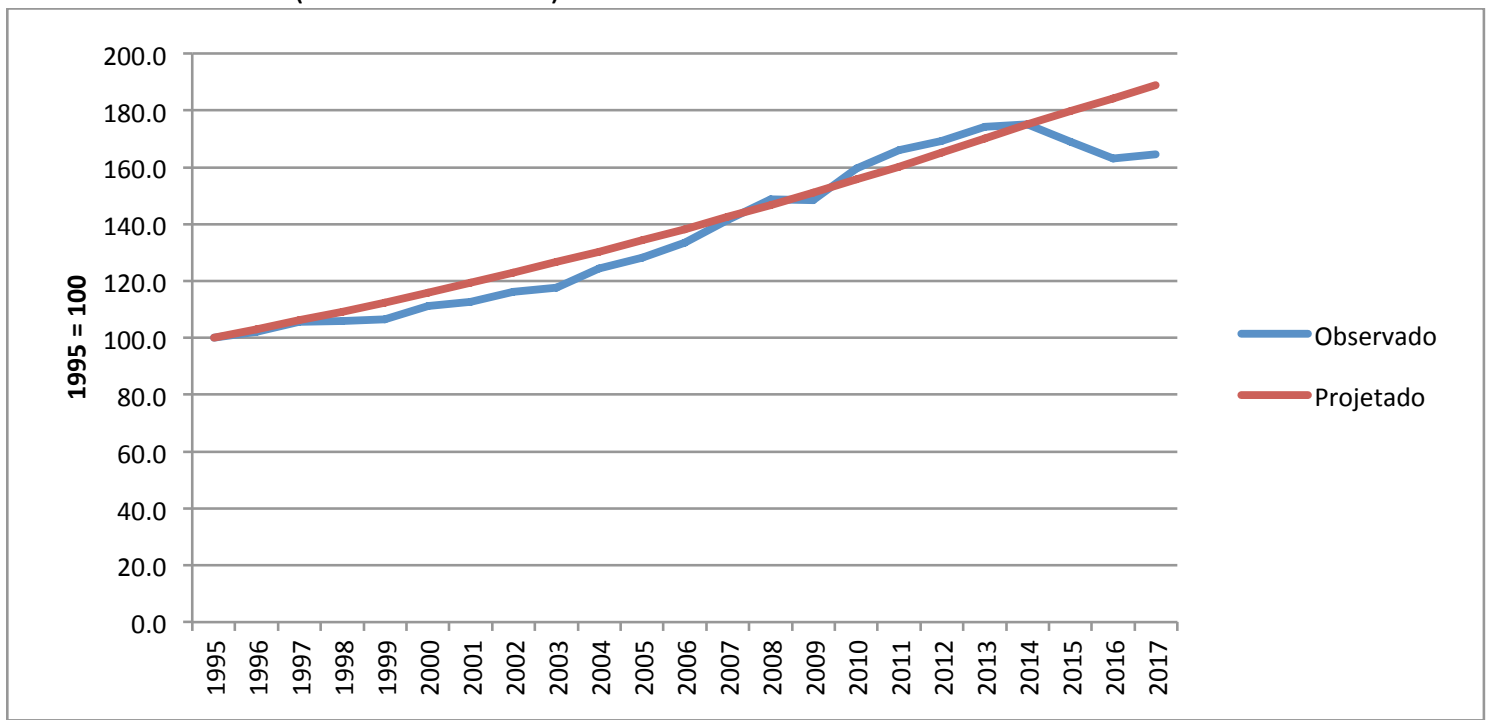

Fonte: Elaboração própria a partir de dados do IBGE.

No caso do Brasil, verificou-se que o nível de atividade econômica esteve acima da sua tendência histórica somente nos anos 2008 e 2010-2014. A perda de dinamismo econômico no período 1995-2003 foi mais intensa do que em Minas Gerais. Embora a recuperação do crescimento a partir de 2004 tenha favorecido relativamente mais as economias estaduais das Regiões Norte, Centro-Oeste e Nordeste, no conjunto do país o ponto de partida para essa recuperação estava bem mais distanciado da tendência de longo prazo do que no caso específico da economia de Minas Gerais. Assim, em que pese o crescimento econômico particularmente vigoroso no Brasil durante o período 2003-2008, ele foi apenas suficiente para que o hiato negativo do nível de atividade observado em relação ao tendencial fosse progressivamente fechado (Gráfico 3).

A tabela 1 apresenta os dados observados e projetados para a tendência de longo prazo da taxa de variação do índice de volume do PIB em Minas Gerais e no Brasil. A análise se concentra nos três anos para os quais se busca estimar a "perda" do PIB associada com a crise econômica de 2015-2017.

Tabela 1. Taxas de variação anual do índice de volume do Produto Interno Bruto (observado e tendencial) - Minas Gerais e Brasil - 2015-2017 - (\% a.a.)

\begin{tabular}{lccc}
\hline \multicolumn{1}{c}{ Especificação } & 2015 & 2016 & 2017 \\
\hline Minas Gerais & & & \\
\hline Observado & $-4,26$ & $-1,80$ & 0,60 \\
Tendencial & 2,26 & 2,23 & 2,20 \\
\hline Brasil & & & 0,99 \\
\hline Observado & $-3,55$ & $-3,46$ & 2,54 \\
Tendencial & 2,61 & 2,57 & 2 \\
\hline
\end{tabular}

Fonte: Elaboração própria a partir de dados da FJP-MG e do IBGE.

Com base nesses dados, foi estimado o valor a preços constantes de 2017 do PIB observado e do tendencial para Minas Gerais e para o Brasil no triênio 2015-2017. A diferença entre os dois valores corresponde à estimativa da "perda" de renda agregada a preços de 2017, tanto no país quanto na economia estadual. 
A "perda" de PIB pode ser decomposta em dois fatores principais: a renda perdida com a queda do nível de atividade econômica em relação ao ano-base de 2014 (perda 1), que por hipótese corresponde ao momento em que o PIB observado e o tendencial coincidiram; e a perda do ganho de produção que teria ocorrido (perda 2), em relação a 2014, caso a economia tivesse continuado a crescer conforme a sua tendência histórica. Os gráficos 4 e 5, a seguir, sumarizam essas informações para a economia de Minas Gerais e do Brasil, respectivamente.

Gráfico 4. PIB observado e estimativa da perda de PIB, R\$ bilhões a preços constantes de 2017 (Minas Gerais)

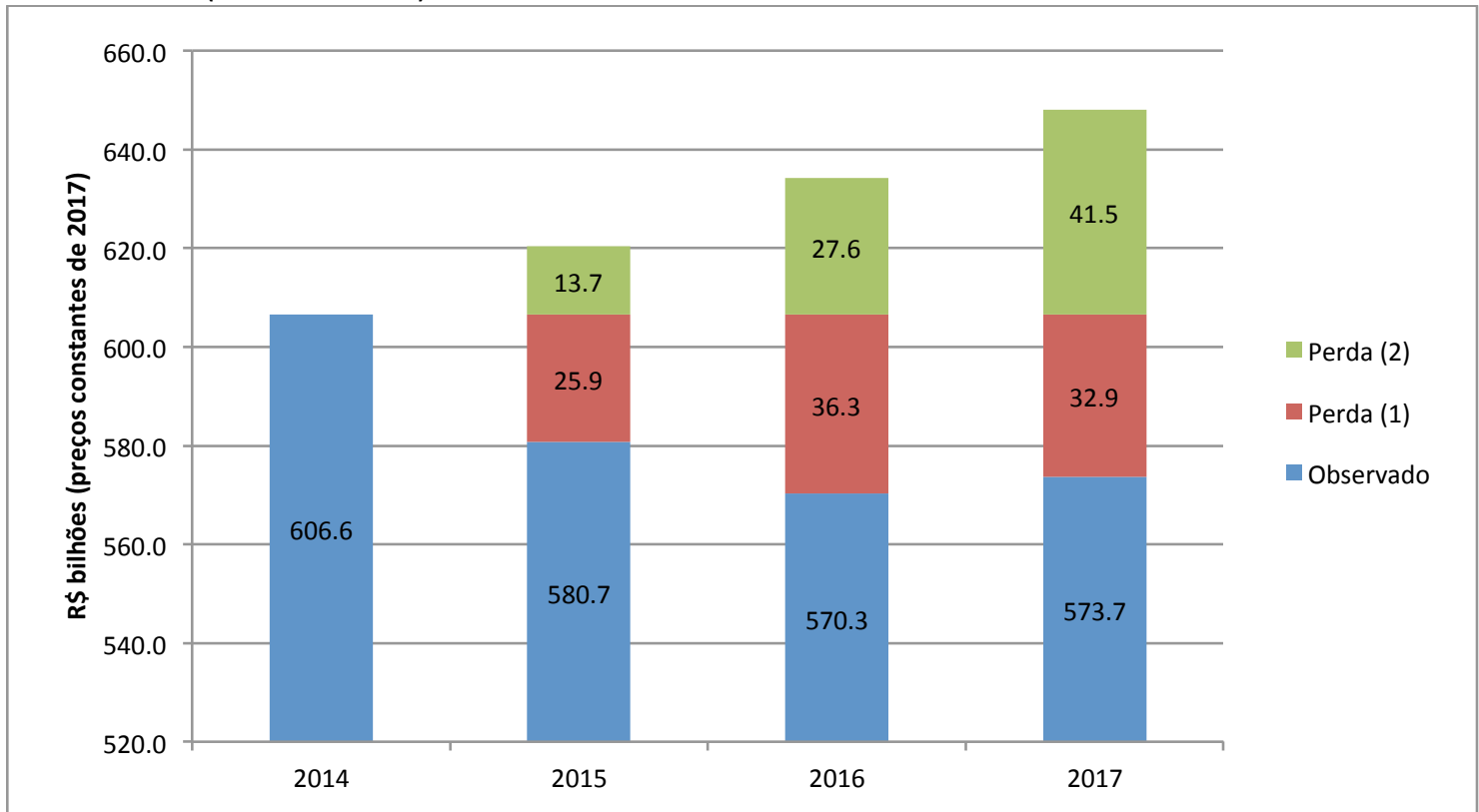

Fonte: Elaboração própria a partir de dados da FJP-MG.

Gráfico 5: PIB observado e estimativa da perda de PIB, R\$ bilhões a preços constantes de 2017 (Brasil)

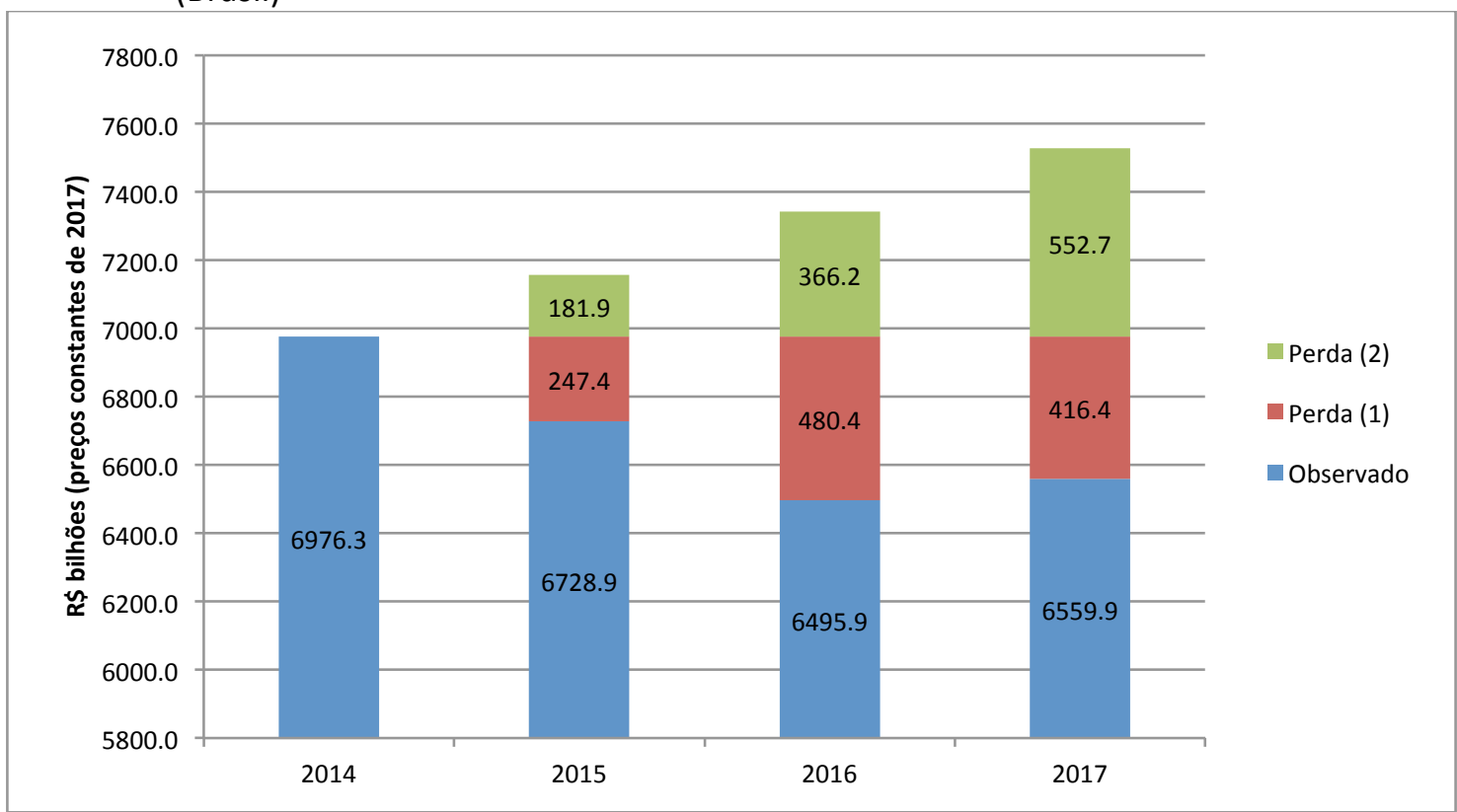

Fonte: Elaboração própria a partir de dados do IBGE. 
Em relação ao PIB real observado (mensurado a preços constantes de 2017), a perda de PIB associada com a crise econômica do triênio 2015-2017 correspondeu, no caso de Minas Gerais, a 6,8\% em 2015, 11,2\% em 2016 e 13,0\% em 2017. No caso do Brasil, a 6,4\% do PIB observado em 2015, 13,0\% em 2016 e 14,8\% em 2017. Considerando a perda acumulada durante os três anos, em Minas Gerais, a perda acumulada, de R\$177,9 bilhões, correspondeu a 10,3\% de todo o PIB gerado ao longo de 2015-2017. Para o conjunto da economia brasileira, a perda total foi de $\mathrm{R} \$ 2.244,9$ bilhões, correspondente a $11,3 \%$ do PIB efetivamente gerado na soma do período.

Na decomposição da perda do PIB, percebe-se que o maior impacto inicial se deu pela retração do nível de atividade em relação ao atingido em 2014. No entanto, à medida que o PIB real volte a apresentar uma variação positiva, como em 2017, essa diferença em relação ao valor de 2014 começa a diminuir, em termos absolutos e relativos, até que eventualmente venha a ser eliminada. Já o componente da perda de PIB relacionado com o crescimento não realizado será ampliado anualmente enquanto a taxa de crescimento observada, mesmo que positiva, for inferior à da projeção da tendência de longo prazo. Assim, no fluxo anual de 2017, as taxas de crescimento real do PIB observadas em Minas Gerais e no Brasil foram menores que as projetadas para aquele ano, de respectivamente $2,2 \%$ e $2,5 \%$ (tab. 1). Logo, a perda de PIB associada com o crescimento tendencial não realizado ampliou-se de $R \$ 27,6$ bilhões, em 2016, para R\$ 41,5 bilhões, em 2017, em Minas Gerais, e, no mesmo período, $R \$ 366,2$ bilhões em 2016 para $R \$ 552,7$ bilhões em 2017, no Brasil (graf. 4 e 5).

Esse fator, que reflete a frustração do crescimento tendencial, somente seria eliminado num fluxo anual caso a economia crescesse acima do ritmo da tendência histórica por um período suficientemente prolongado (possivelmente, mais de uma década). No entanto, essa condição é altamente improvável no atual cenário brasileiro, na ausência de profundas reformas, no âmbito da política, das instituições, da sociedade e da economia.

A discussão dos custos econômicos permanentes, de longo prazo, resultantes de recessões no curto prazo, há muito tempo ocupa a agenda de pesquisa em macroeconomia. Mais recentemente, recebeu a contribuição importante de novas evidências empíricas que indicam, numa amostra de 190 países, que as crises financeiras e as crises políticas geram uma perda permanente da magnitude de $5 \%$ do PIB, no caso de crises mais simples, e de até $15 \%$ quando combinam elementos de crise financeira e cambial com distúrbios políticos (CERRA \& SAXENA, 2008, 2017; OBTSFELD, 2018).

\section{Perda de PIB em Minas Gerais: impacto fiscal}

As receitas fiscais (ou tributárias) são parte das receitas orçamentárias. Mais precisamente, as receitas orçamentárias são agrupadas em receitas correntes, que é composta pelas receitas tributárias, de contribuições, patrimonial, industrial, de serviços e ainda as provenientes de outras pessoas de direito público ou privado (transferências correntes); e em receitas de capital, que se subdividem em operações de empréstimos, alienação de bens, transferências de capital, amortizações de empréstimos e outras receitas de capital. As receitas tributárias respondem pela maior parcela da arrecadação do estado de Minas Gerais. Em 2017, por exemplo, elas corresponderam a 60\% do total da arrecadação (Gráfico 2). 
Existe um vínculo muito forte entre a obtenção das receitas tributárias e o desempenho econômico estadual e do país, na medida em que elas estão vinculadas à produção e à circulação de bens e serviços. Em particular, parcela considerável (próximo a 80\%) das receitas tributárias estaduais depende do Imposto sobre Circulação de Mercadorias e Serviços (ICMS).

Gráfico 6. Estrutura das receitas, Minas Gerais (2017)

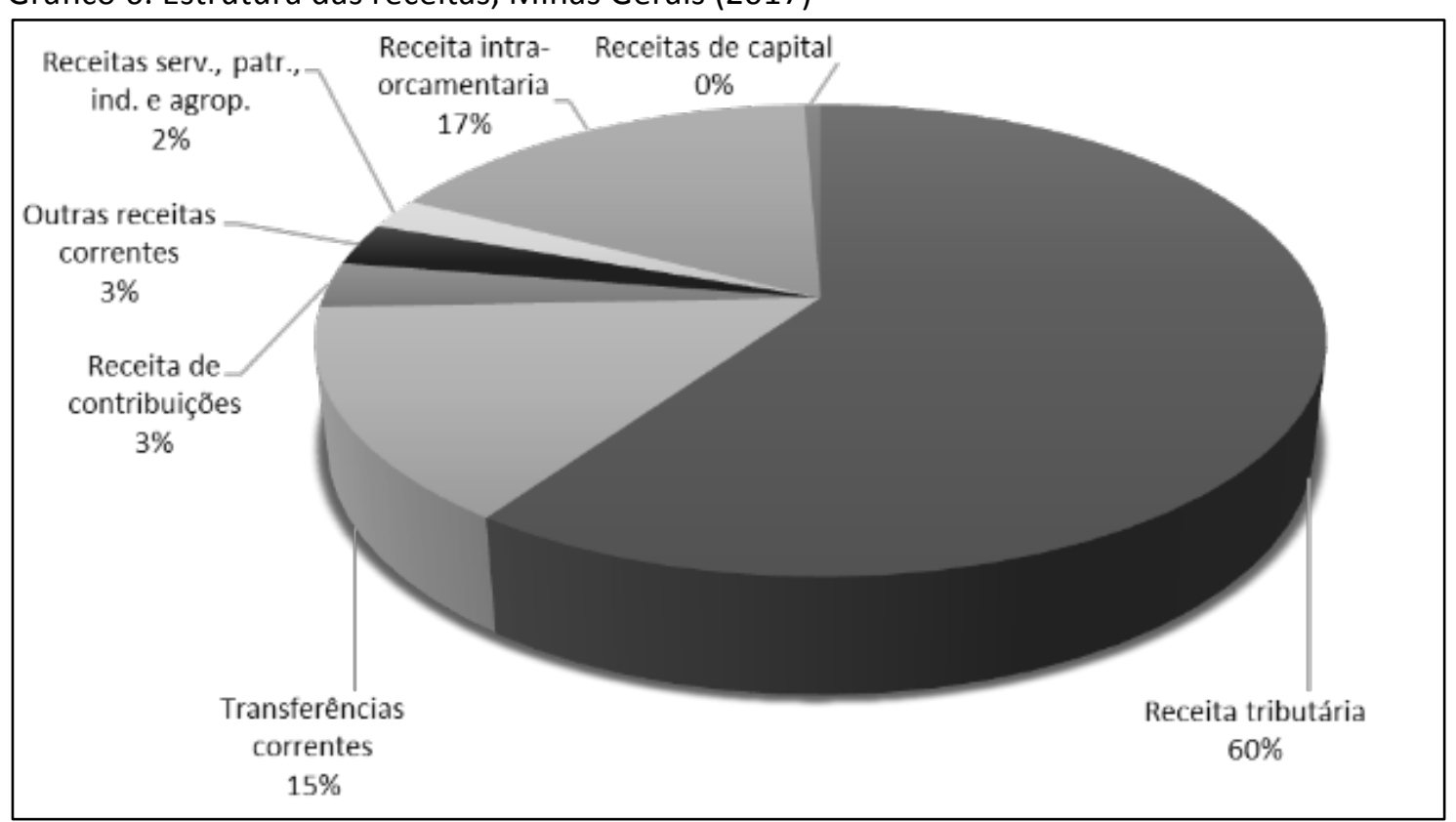

Fonte: Elaboração própria a partir de dados do Siafi-MG.

Nota: na estrutura de receitas de 2017 não foi considerada a dedução das receitas correntes.

Dessa forma, para avaliar o impacto da crise econômica sobre as finanças públicas estaduais em Minas Gerais, é necessário estimar, mesmo que aproximadamente, qual foi a frustração de receita derivada da queda do nível de atividade da economia. Para esse objetivo, utiliza-se a proporção da arrecadação de ICMS no PIB estadual em 2014 como um indicador da arrecadação que potencialmente se teria realizado caso o crescimento do PIB tivesse seguido a sua tendência histórica no período 2015-2017.

Essa estimativa será, então, confrontada com a arrecadação efetivamente observada. O resultado é justamente a receita que se deixou de arrecadar. Para a realização desse exercício, calculou-se o valor do PIB tendencial a preços correntes no período de referência. A Tabela 2 sintetiza os resultados desses cálculos.

Os resultados indicam que, somente no ano de 2015, R\$ 3,2 bilhões de ICMS deixaram de ser arrecadados em Minas Gerais por conta da queda do nível de atividade econômica. Nos anos seguintes, as perdas foram de de R\$ 3,5 bilhões, em 2016, e de R\$ 1,4 bilhão, em 2017. No triênio, a perda total foi de $\mathrm{R} \$ 8,0$ bilhões. Como proporção do total efetivamente arrecadado, essas perdas equivaleram a 8,3\% em 2015 e em 2016, e a 2,9 \% em 2017. 
Tabela 2. PIB observado, PIB tendencial e arrecadação de ICMS em Minas Gerais (R\$ bilhões a preços correntes)

\begin{tabular}{lrrrr}
\hline Especificação & 2014 & 2015 & 2016 & \multicolumn{1}{c}{2017} \\
\hline Arrecadação de ICMS & & & & \\
Valores correntes (1) & 38,3 & 37,9 & 41,9 & 46,7 \\
PIB observado & 516,6 & 519,3 & 550,3 & 573,7 \\
PIB tendencial & 516,6 & 554,7 & 612,0 & 648,1 \\
Proporção da Arrecadação de ICMS & & & & \\
\% no PIB observado & 7,4 & 7,3 & 7,6 & 8,1 \\
\% no PIB tendencial & 7,4 & 6,8 & 6,8 & 7,2 \\
Tendência da Arrecadação de ICMS (2) & 38,3 & 41,1 & 45,4 & 48,0 \\
Perda da Arrecadação & 0,0 & $-3,2$ & $-3,5$ & $-1,4$ \\
de ICMS (3) = (1) - (2) & & & & \\
Perda da Arrecadação & 0,0 & 8,3 & 8,3 & 2,9 \\
de ICMS (\% da Realizada) & & & & \\
\hline Forata
\end{tabular}

Fonte: Elaboração própria.

Notas: (1) Dados sobre a arrecadação de ICMS obtidos do Boletim de Arrecadação do Conselho Nacional de Política Fazendária (CONFAZ/MF), incluem a cobrança de dívida ativa. Cf.: www.confaz.fazenda.gov.br/legislacao/boletim-do-icms. Acesso em 28/03/2018. (2) Eventuais diferenças entre as somas dos componentes e os totais apresentados se devem ao arredondamento de casas decimais.

Esse mesmo exercício foi realizado para a arrecadação do IPI e da Cofins e revelou que o impacto fiscal da crise econômica sobre essas fontes de receita foi ainda mais acentuado do que no caso do ICMS (Tabela 3).

Tabela 3. Arrecadação observada e tendencial de IPI e Cofins em Minas Gerais (R\$ bilhões a preços correntes)

\begin{tabular}{|c|c|c|c|c|}
\hline Especificação & 2014 & 2015 & 2016 & 2017 \\
\hline \multicolumn{5}{|l|}{ Arrecadação de IPI } \\
\hline Valores correntes (1) & 6,0 & 5,6 & 6,1 & 6,1 \\
\hline Projeção da arrecadação (2) & 6,0 & 6,4 & 7,1 & 7,5 \\
\hline Perda da Arrecadação & 0,0 & $-0,9$ & $-1, \mathrm{C}$ & $-1,4$ \\
\hline \multicolumn{5}{|l|}{ de IPI (3) = (2) - (1) } \\
\hline Perda da Arrecadação & 0,0 & 15,3 & 15,8 & 23,2 \\
\hline \multicolumn{5}{|l|}{ de IPI (\% da Realizada) } \\
\hline \multicolumn{5}{|l|}{ Arrecadação de Cofins } \\
\hline Valores correntes (1) & 10,5 & 10,2 & 9,8 & 9,8 \\
\hline Projeção da arrecadação (2) & 10,5 & 11,3 & 12,4 & 13,2 \\
\hline Perda da Arrecadação & 0,0 & $-1,1$ & $-2,6$ & $-3,4$ \\
\hline \multicolumn{5}{|l|}{ de Cofins (3) = (2) - (1) } \\
\hline Perda da Arrecadação & 0,0 & 10,8 & 26,5 & 34,8 \\
\hline de Cofins (\% da Realizada) & & & & \\
\hline
\end{tabular}

Fonte: Elaboração própria partir de dados

Nota: (1) Dados sobre a arrecadação de IPI e COFINS obtidos da Receita Federal.

Cf.: idg.receita.fazenda.gov.br/dados/receitadata/arrecadacao/arrecadacao-por-estado. Acesso em 28/03/2018. (2) Eventuais diferenças entre as somas dos componentes e os totais apresentados se devem ao arredondamento de casas decimais.

Constata-se, então, que houve expressiva perda de arrecadação tributária decorrente da queda da atividade econômica. No total, foram quase 20 bilhões de perca de ICMS, IPI e Cofins 
no período de 2015-2017. Apenas em 2017, deixou-se de arrecadar cerca de 6.2 bilhões, que corresponde a mais de 60\% do déficit orçamentário de 9,7 bilhões registrado em 2017.

Todavia, essa perda projetada não leva em consideração o esforço de arrecadação realizado pelo governo estadual. Ou seja, ela seria ainda maior caso o governo não tivesse adotado medidas para aumentar suas receitas. Dentre elas, menciona-se o aumento do ICMS sobre diversos produtos considerados supérfluos, tais como ração tipo pet, perfumes e cosméticos, etc. (Lei 21781, de 01 de outubro de 2015) e o plano de regularização de créditos tributários (Lei 22.549 de junho de 2017), cujo objetivo era regularizar, em condições especiais, débitos tributários, incluindo os relativos ao ICMS.

A tabela 4 discrimina a taxa de crescimento nominal das receitas tributárias, comparando-a à taxa de crescimento da receita total e da inflação. Nota-se que, tanto em 2016 quanto em 2017, o crescimento das receitas tributárias se deu em termos reais (acima da inflação observada). Contudo, em 2015, o crescimento foi menor do que inflação, em aproximadamente sete pontos percentuais. Por isso, a média trienal é bastante próxima do crescimento médio dos preços.

Tabela 4. Crescimento da Receita Efetivada, principais subcategorias - 2015-2017 - (\%)

\begin{tabular}{lrrrc}
\hline \multicolumn{1}{c}{ Especificação } & 2015 & 2016 & 2017 & $\begin{array}{c}\text { Média do triênio } \\
(2015-2017)\end{array}$ \\
\hline Receita tributárias & 1,98 & 10,35 & 9,53 & 7,29 \\
Receita total & $\mathbf{3 , 8 3}$ & $\mathbf{1 0 , 2 6}$ & $\mathbf{5 , 5 5}$ & $\mathbf{6 , 5 4}$ \\
Inflação (IPCA) & $\mathbf{1 0 , 6 7}$ & $\mathbf{6 , 2 9}$ & $\mathbf{2 , 9 5}$ & $\mathbf{6 , 6 4}$ \\
PIB-MG (nominal) & $\mathbf{5 , 2 1}$ & $\mathbf{5 , 9 6}$ & $\mathbf{4 , 2 4}$ & $\mathbf{3 , 5 7}$ \\
\hline
\end{tabular}

Fonte: Elaboração própria a partir de dados do Siafi-MG.

Adicionalmente, observa-se que, em 2016 e 2017, a receita tributária se desacelerou (acelerou) menos (mais) do que a PIB. Esse desempenho favorável foi alcançado a partir de medidas de curto prazo mencionadas anteriormente. Contudo, o esforço de aumento de arrecadação do governo não foi suficiente para contar a deterioração das contas públicas.

\section{Crise fiscal e dinâmica das despesas orçamentárias: 2015-2017}

Desde o início da recessão econômica em 2014, o estado de Minas Gerais tem apresentado sucessivos déficits fiscais. Na realidade, em 2013 o estado já registrava déficit próximo a 1 bilhão. A partir de então, o resultado fiscal se deteriorou rapidamente, de modo que, em 2017, o valor do déficit foi superior a 9 bilhões.

Aliado aos recorrentes déficits houve piora em indicadores-chaves da Lei de Responsabilidade Fiscal (LRF). A relação entre gastos com pessoal e receita corrente líquida, no poder executivo, está bastante próxima ao limite de $50 \%$ permitido pela legislação. 0 mesmo vale para a relação entre a dívida consolidada líquida e a receita corrente líquida, cujo limite é de $200 \%$.

Em parte, a queda da arrecadação, discutida na seção anterior, contribui para a deterioração fiscal das contas públicas. Mas, por outro lado, a dinâmica das despesas também influenciou decisivamente os resultados orçamentários. 
As despesas orçamentárias são classificadas de acordo com a categoria econômica: correntes e de investimento. As despesas correntes correspondem à, aproximadamente, $90 \%$ do total, sendo que a maior parte se refere aos gastos com pessoal e encargos sociais e a outras despesas correntes (gráf. 7). Ainda que as despesas de investimento representem fração pequena da despesa total, ela constitui a principal variável de ajuste fiscal (Pires, 2017). Assim, é importante analisar seu comportamento ${ }^{12}$.

Gráfico 7. Estrutura das despesas - Minas Gerais - 2017 - (\%)

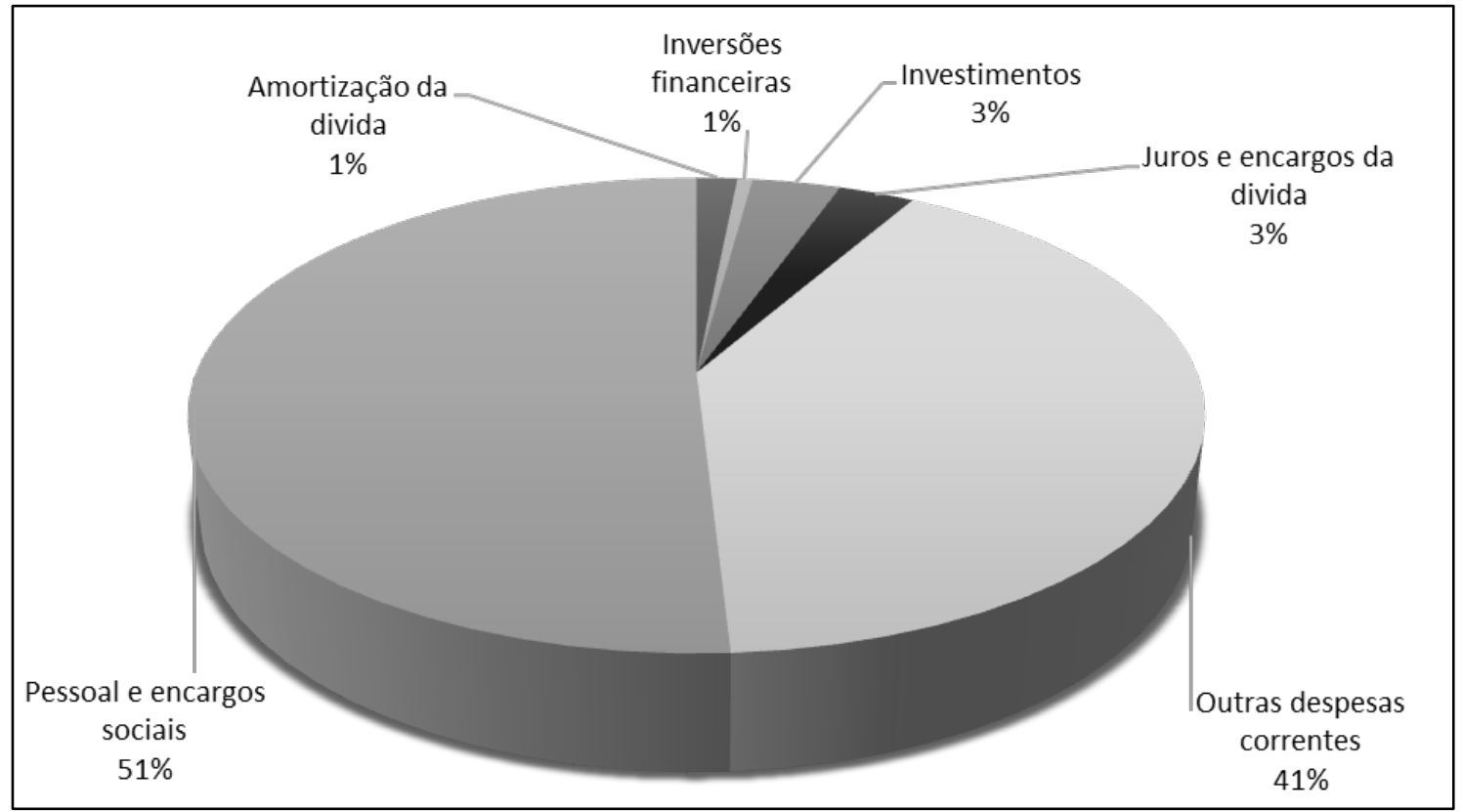

Fonte: Elaboração própria a partir de dados do Siafi-MG.

Em 2015, o crescimento dos gastos com despesas correntes foi puxado pelos gastos com pessoal e encargos sociais (ver Tab.5). Existem duas explicações para esse crescimento. A primeira é o próprio crescimento vegetativo da folha. A segunda são os reajustes ${ }^{13}$ escalonados de salários e vencimentos de várias carreiras, aprovados entre 2011 e 2014 na gestão do governador Antônio Anastasia (Leis 19.576, de 16/08/11, 20.748, de 25/06/13; 21.216 , de $07 / 05 / 14 ; 21.167$, de 17/01/14, etc.). Entretanto, em contraposição ao observado em 2015, o ritmo de crescimento desses gastos se desacelerou em 2016 e 2017.

Em 2016, os gastos com despesas de juros e encargos sociais decresceram em quase R\$ 2 bilhões. Tal queda se associa à renegociação da dívida dos estados com a União, materializada na lei complementar 156, de 28/12/16 (a maior parcela da dívida estadual é com a União). Logo, essa é a principal explicação para a queda de mais de 4 pontos percentuais na taxa de crescimento das despesas correntes em 2016. Assim, já em 2017, o aumento dos gastos com despesas correntes voltou a crescer (ver Tabela 5).

\footnotetext{
${ }^{12}$ Ocioso notar que dada sua pequena magnitude, a oscilação da média dos gastos é muito maior.

${ }^{13} \mathrm{Na}$ atual gestão do governador Fernando Pimentel, houve reajuste dos salários dos servidores da educação (lei 22.062, 20/04/16).
} 
Tabela 5. Crescimento da Despesa Orçamentária por principais Grupos de Natureza (\%)

\begin{tabular}{lcccc}
\hline \multicolumn{1}{c}{ Especificação } & 2015 & 2016 & 2017 & $\begin{array}{c}\text { Média do triênio } \\
(\mathbf{2 0 0 1 5 - 2 0 1 7 )}\end{array}$ \\
\hline Despesas de Capital & $\mathbf{( 1 6 , 5 8 )}$ & $\mathbf{( 3 5 , 6 0 )}$ & $\mathbf{1 7 , 1 3}$ & $\mathbf{( - 1 1 , 6 8 )}$ \\
Investimentos & $(23,55)$ & $(13,09)$ & 18,66 & $(-5,99)$ \\
Despesas Correntes & $\mathbf{1 6 , 4 5}$ & $\mathbf{7 , 1 1}$ & $\mathbf{1 1 , 3 4}$ & $\mathbf{1 1 , 6 3}$ \\
Outras despesas correntes & 13,30 & 12,72 & 13,98 & 13,34 \\
Pessoal e encargos sociais & 18,82 & 8,03 & 6,66 & 11,17 \\
Total Geral & $\mathbf{1 2 , 7 2}$ & $\mathbf{3 , 5 4}$ & $\mathbf{1 1 , 6 4}$ & $\mathbf{9 , 3 0}$ \\
Média da Inflação (IPCA) & $\mathbf{1 0 , 6 7}$ & $\mathbf{6 , 2 9}$ & $\mathbf{2 , 9 5}$ & $\mathbf{6 , 6 4}$ \\
\hline
\end{tabular}

Fonte: Elaboração própria a partir de dados do Siafi-MG.

Já o ritmo de crescimento dos gastos em outras despesas correntes se manteve praticamente constante em todo o período. Os aportes para a cobertura do déficit atuarial do Regime Próprio de Previdência Social (RPPS), que vem crescendo a taxas superiores a 30\% a.a., contribuíram significativamente para o comportamento dessa categoria de despesa (em 2017, cerca de $R \$ 10$ bilhões foram gastos nesse item, representando cerca de $1 / 4$ do total). Assim, os gastos previdenciários se conformam como um problema estrutural, que está se agravando nos últimos anos, ainda sem solução.

$\mathrm{Na}$ outra ponta, a contenção das despesas de capital foi bastante acentuada. No total, considerando os gastos com amortizações, inversões financeiras e investimento, a variação média foi negativa em $11 \%$ no último triênio. A queda dos gastos com amortizações se explica em função da renegociação das dívidas estaduais com a União e com o Banco Nacional de Desenvolvimento Econômico e Social (BNDES). As inversões financeiras se referem, grosso modo, a despesas orçamentárias com a aquisição de imóveis ou bens de capital já em utilização e aquisição de títulos representativos do capital de empresas ou entidades de qualquer espécie já constituídas. Elas também decresceram.

Além disso, mais relevante do que a retração desses gastos foi a queda dos investimentos. Tais despesas são tidas como a principal variável de política fiscal para administrar o ciclo econômico. Os multiplicadores fiscais associados ao investimento são superiores a um, sobretudo quando existe elevada capacidade ociosa (Orair e Siqueira, 2016). Isso quer dizer que gastos de investimento costumam gerar crescimento mais do que proporcional ao montante dispendido.

Contudo, a maior parte das despesas não é discricionária ${ }^{14}$. Dessa forma, usualmente, em épocas de crise econômica e fiscal, as despesas com investimentos são contingenciadas. Tal fato é confirmado no caso mineiro, conforme a tabela 5.

\footnotetext{
${ }^{14}$ De acordo com a Lei de Diretrizes Orçamentárias (LDO), a base contingenciável corresponde ao total das dotações estabelecidas na lei orçamentária de 2018, excluídas: as vinculações constitucionais; as obrigações legais; as despesas com o pagamento de precatórios e sentenças judiciais; as despesas com pessoal e encargos sociais; as despesas com juros e encargos da dívida; as despesas com amortização da dívida; as despesas com auxílio-doença, auxílio-funeral, auxílio-alimentação, auxíliotransporte e auxílio-fardamento financiados com recursos ordinários; as despesas com o Pasep.
} 
Depois de dois anos de queda consecutiva, houve crescimento, em 2017, de cerca de 18\%, sendo que, em termos nominais, o valor observado é ligeiramente superior ao de 2015. Inclusive, essa retomada dos gastos com investimentos coincide com a retomada do (fraco) crescimento da economia mineira.

Contudo, os gastos com investimento ainda estão longe do patamar pré-crise. Em última instância, essa desaceleração dos investimentos estaduais pode estar contribuindo para a recuperação lenta da atividade econômica.

\section{Considerações finais}

A trajetória recente do PIB e dos indicadores fiscais do estado de Minas Gerais sugere que a reversão do quadro atual é bastante desafiadora. No último triênio, mesmo com a desaceleração de gastos com pessoal e com investimentos, foram registrados sucessivos déficit fiscais.

Por um lado, a queda acumulada de 6,1\% da atividade econômica no biênio 2015-2016 provocou a desaceleração das receitas. Por outro, o crescimento das despesas, apesar da crise econômica e fiscal, foi superior ao da inflação.

Pesa desfavoravelmente nessa equação a rigidez dos gastos públicos. Os gastos com pessoal, amortização e juros da dívida representaram, em 2017, mais de 50\% das despesas. Adicionalmente, os governos estaduais devem cumprir os gastos mínimos constitucionais na educação, saúde, ciência tecnologia, etc. Soma-se, ainda, no caso mineiro, o crescente gasto com a cobertura dos déficits do regime de previdência do RPPS, equivalente a aproximadamente $10 \%$ dos gastos totais nesse mesmo ano. Portanto, a margem de manobra do governo estadual é baixa.

Nesse cenário, a retomada extremamente lenta (provavelmente a mais lenta da história) da economia, aliada à rigidez das despesas, impede o ajuste das contas públicas. Os esforços fiscais empreendidos pelo governo mineiro no último triênio contribuíram tanto para impedir uma queda de arrecadação maior como para conter o avanço dos gastos públicos, em particular nas despesas com pessoal e com investimentos. No entanto, dificilmente tais medidas reverterão a tendência de agravamento das contas públicas (pelo menos, a médio prazo). Imagina-se, então, que, em breve, a União, que concentra a maior parte da arrecadação tributária, contribua para equacionar a situação (assim como no Rio de Janeiro).

\section{Referências}

Barbosa Filho, F., Turra, C., Wajnman, S. e Guimarães, R. (2016) “Transição demográfica, oferta de trabalho e crescimento econômico no Brasil”, In: R. Bonelli e F. Veloso (Orgs.) $A$ crise de crescimento do Brasil. Rio de Janeiro: Elsevier, p. 87-110.

Brasil (2001) Lei Complementar 101, de 4 de mai. de 2001. Estabelece normas de finanças públicas voltadas para a responsabilidade na gestão fiscal e dá outras providências. Brasília, DF. 
Brasil (2016) Lei Complementar 156, de 28 de dez. de 2016. Estabelece o Plano de Auxílio aos Estados e ao Distrito Federal e medidas de estímulo ao reequilíbrio fiscal; e altera a Lei Complementar no 148, de 25 de novembro de 2014, a Lei no 9.496, de 11 de setembro de 1997, a Medida Provisória no 2.192-70, de 24 de agosto de 2001, a Lei no 8.727, de 5 de novembro de 1993, e a Lei Complementar no 101, de 4 de maio de 2000. Brasília, DF.

CONFAZ (2018) Boletim de Arrecadação do Conselho Nacional de Política Fazendária, Conselho Nacional de Política Fazendária, Brasília, DF. Disponível em www.confaz.fazenda.gov.br/legislacao/boletim-do-icms. Acessado em 28/03/2018.

FIRJAM (2017) A situação fiscal dos estados brasileiros. Rio de Janeiro: FIRJAM, Conjuntura econômica.

FJP (2018) PIB trimestral de Minas Gerais: 1o trimestre de 2018. Belo Horizonte: FJP, Série Indicadores FJP, n. 8.

Gordon, R. (2017) The rise and fall of American growth. Princeton, NJ: Princeton University Press.

IBGE (2006) Estatísticas do Século XX. Rio de Janeiro: Centro de Documentação e Disseminação de Informações, $557 \mathrm{p}$.

IBGE (2008) Projeção da população do Brasil por sexo e idade 1980-2050: Revisão 2008, Coordenação de População e Indicadores Sociais, Série Relatórios Metodológicos, v. 24

IBGE (2013) Projeções da população: Brasil e Unidades da Federação, Coordenação de População e Indicadores Sociais, Série Relatórios Metodológicos, v. 40.

Lopreato, F. (2008) Finanças estaduais: alguns avanços, mas... (os exemplos de São Paulo, Rio de Janeiro e Rio Grande do Sul). Textos para Discussão, n.145, Campinas: Editora Unicamp.

Minas Gerais (2013) Lei 20.748, de 25 de jun. Reajusta as tabelas de vencimento básico das carreiras que menciona, institui a gratificação complementar no âmbito da escola de saúde pública do estado de minas gerais - ESP-MG -, institui a carreira de auditor assistencial estadual do sistema único de saúde no estado e dá outras providências, Belo Horizonte, MG.

Minas Gerais (2014) Lei 21.216, de 07 de mai. Fixa o subsídio dos membros da defensoria pública do estado, Belo Horizonte, MG.

Minas Gerais (2014) Lei 21.167, de 17 de jan. Incorpora a gratificação complementar ao vencimento básico dos servidores das carreiras que menciona, cria cargos de provimento efetivo da carreira de analista de hematologia e hemoterapia, a que se refere a lei $\mathrm{n}^{\circ}$ 15.462, de 13 de janeiro de 2005, institui regime de remuneração por subsídio para a carreira de professor de arte e restauro e dá outras providências, Belo Horizonte, MG.

Minas Gerais (2016) Lei 22.062, de 20 de jun. Altera a Lei no 21.710 de 30 de junho de 2015, que dispõe sobre a política remuneratória das carreiras do Grupo de Atividades de 
Educação Básica do Poder Executivo e altera a estrutura da carreira de Professor de Educação Básica e dá outras providências, Belo Horizonte, MG.

Minas Gerais (2017) Lei 21.781, de 01 de out. Altera as Leis nos 6.763, de 26 de dezembro de 1975, 12.729, de 30 de dezembro de 1997, 14.937, de 23 de dezembro de 2003, e 19.976, de 27 de dezembro de 2011, e dá outra providência, Belo Horizonte, MG.

Minas Gerais (2017) Lei 22.549, de 30 de jun. Institui o plano de regularização tributária e dá outras providências. Belo Horizonte, MG.

Minas Gerais (2018) Lei 22.626, de 28 de jul. Dispõe sobre as diretrizes para a elaboração e a execução da lei orçamentária para o exercício de 2018 e acrescenta artigo à Lei no 22.254, de 25 de julho de 2016. Belo Horizonte, MG.

Ministério da Fazenda (2018) Receita Federal: arrecadação por estado. idg.receita.fazenda.gov.br/dados/receitadata/arrecadacao/arrecadacao-por-estado. Acessado em 28/03/2018.

Orair, R. e Siqueira, F. (2016). Investimento público no Brasil: trajetória recente e relações com o ciclo econômico e regime fiscal. IX Prêmio SOF de monografias.

Oreiro, J. e D'Agostini, L. (2017) "Macroeconomic policy regimes, real exchange rate overvaluation, and performance of the Brazilian economy (2003-2015)", Journal of Post Keynesian Economics, 40(1), p.27-42.

Pereira, H., Tanure, T., Teixeira, A. e Missio, F. (2017) “Uma perspectiva crítica do novo regime fiscal para a dinâmica de curto e longo prazo da economia brasileira, Revista de Economia do Centro-Oeste, 3(1), p. 51-69.

Pires, M. (2017). Política fiscal e ciclos econômicos: teoria e experiência recente. Rio de Janeiro: Elsevier, FGV.

Reis, E., Blanco, F., Morandi, L., Medina, M. e Abreu, M. (2006) "Século XX nas Contas Nacionais" In: IBGE (Org.) Estatísticas do Século XX. Rio de Janeiro, IBGE: Centro de Documentação e Disseminação de Informações, p. 509-538.

Rios-Neto, E. (2005) "Questões emergentes na análise demográfica: o caso brasileiro", Revista Brasileira de Estudos Populacionais, 22(2), p. 371-408.

Silva-Filho, T. (2001) Estimando o produto potencial brasileiro: uma abordagem da função de produção, Texto para Discussão, n.17, Brasília: Banco Central do Brasil.

Souza Jr., J. (2005) Produto potencial: conceitos, métodos de estimação e aplicação à economia brasileira, Texto para discussão, n.1130, Brasília: Banco Central do Brasil.

Souza Jr., J. e Caetano, S. (2013) Produto potencial como ferramenta de análise da política monetária e da capacidade de crescimento da economia brasileira. Texto para Discussão, n.1881, Brasília: Banco Central do Brasil. 